ly black populations. The overriding reason is undoubtedly prejudice or racial sensitivity remaining in small southern towns, especially on the part of white businessmen.

A weekly editor said there would be "lifted eyebrows" if a black reporter presented a press card from his paper. Another said it would be "a little awkward" to have a black reporter in a small community. Another said a black would have to prove himself a little more than a white; subconsciously, he said, he would examine his grades, experience, vocabulary, and grooming more closely than if he were white.

One weekly editor, however, said he had attempted to hire a black reporter, but had been outbid. He added that his hiring a black would have had unfavorable repercussions.

Another reason for the low representation of blacks in weeklies is that most have very small editorial staffs, usually two or three persons. "Na one is just a reporter," one weekly editor said. Others said weekly newspapers rarely hire reporters per se, black or white.

The weekly editors reporting receive few, if any, applications from blacks for jobs requiring journalistic skill. They did not predict an increase in opportunities for black journalists in the next 10 to 15 years.

\section{Daily Newspaper Circulation Price Inelastic for 1970-75}

\section{By Gerald L. Grotta}

- Almost 20 years ago, Landau and Davenport stated that: "The sales price of a newspaper, therefore, is expressed neither by the interaction between Sup-

\footnotetext{
1 Edmund Landau and John Scott Davenport. "Price Anomalies of the Mass Media," Journalism Quartert.y, 36:291-4 (1959), p. 292.

2"90\% in Survey Receptive to ise a copy, Gallup Says," Editor \& Aublisher. April 24, 1971, p. II

Jjeff Clark, "Circulation Increase Despite Higher Subscription Price," Editor \& Publisher, Feb. 14, 1976, p. 32.

rbid.
}

ply and Demand nor by a relationship to production cost factors. Price determination is purely arbitrary." phasis added)

During the 1970s, newsstand and subscription prices rose, apparently in response to pressure from spiraling costs compounded by an economic slump which affected advertising revenues. The increases were made reluctantly, in spite of mounting evidence of a highly inelastic demand curve. As early as 1961, Gallup advised newspaper publishers that a majority of their readers were receptive to a 15-cent-a-copy price, although most newspapers then charged only 5 cents. ${ }^{2}$ As recently as the beginning of 1971 , only 148 of the 1,742 daily newspapers in the country were charging the price that Gallup had assured them was "safe" 10 years before. It was not until 1974 that even a majority of the daily newspapers reached the 15-cent price.

In 1976, Clark reported results of circulation and price changes for a random sample of 202 daily newspapers. He found that in $59.4 \%$ of the cases, circulation continued to increase as subscription prices increased, and in only $39.3 \%$ of the cases did circulation decrease. ${ }^{3}$ He concluded that although there would be a point of diminishing return in increasing subscription rates, "this point apparently has not been reached by most newspapers in the United States, particularly by newspapers with circulations of 50,000 or less." 4

\section{The Hypothesis}

A pilot study was conducted during the spring of 1976 as an initial step in determining the elasticity of demand for newspaper circulation, in an attempt to provide more precise economic data for decision-making in the newspaper indus-

\footnotetext{
- Dr. Grotta, formerly on the journalism faculty at the University of Oklahoma, is Vice President of RMH Research, Inc., Ridgewood, N.J. This article is based on a paper presented at the Association for Education in Journalism convention at the University of Maryland in 1976.
} 
try. It was hypothesized that the demand curve for circulation would be highly inelastic; i.e., a given percentage increase in price would not lead to a corresponding percentage decrease in circulation.

\section{Methodology}

Data on changes in circulation, percopy price and population of the area in which the newspaper is published were collected for all daily newspapers published in the United States in both 1970 and 1975.5

It was assumed that there is a relationship between per-copy prices and home-delivery subscription rates, although the relationship obviously is not perfect. Also, individual newspapers vary greatly in circulation policies. However, for this pilot study, it was assumed that by using the universe of all newspapers, individual special circumstances would be randomly distributed and tend to cancel each other. Population of the area in which the newspaper is published was included as a concomitant variable.

The data were subjected to both descriptive and regression analyses, using computer program SPSS. ${ }^{\circ}$ Analyses were first made on all newspapers, and then separate runs were made on morning, evening, Sunday and all-day newspapers to determine if elasticity estimates varied among the various types of newspapers.

\section{Results}

The hypothesis received strong support. In all cases, population changes correlated positively with circulation changes, as was expected. This means that as population increased, circulation tended to increase. Price changes tended to correlate negatively with circulation changes, indicating that circulation decreased as price increased, with population changes held constant. However, none of the correlations was significant at the .05 level.

More important, though, the correlation between percentage price change and percentage circulation change was very low in all analyses. This indicates that a relatively large percentage increase in price resulted in a much smaller percentage decrease in circulation.

All Newspapers. A total of 2,194 newspapers published in both 1970 and 1975 were analyzed as a group. The number is higher than the usual figure of about 1,750 because newspapers with the same name with morning, evening, and/or Sunday editions were counted as separate papers for the analyses. The total included 290 morning newspapers or editions, 1,334 evening, 546 Sunday, and 24 all-day.

A summary of changes for all newspapers is presented in Table 1.

During the six-year period, mean circulation increase was $9.9 \%$, population increase was $6 \%$ and price increase was $41.1 \%$. If the demand for newspaper circulation had unitary elasticity, we would expect to find a $41.1 \%$ decrease in circulation with a $41.1 \%$ increase in price. Obviously, this was not the case. Although total circulation did increase, however, when population change is held constant, the increase in price resulted in a minor decrease in circulation.

Data next were subjected to multiple regression analysis to determine the relationship between price change and circulation change. Results of the regression for all newspapers are presented in Table 2.

The formula for the regression equation can be expressed:

$$
\mathbf{Y}^{\prime}=\mathbf{A}+\mathbf{x} 1 \mathrm{~B} 1+\mathrm{x} 2 \mathrm{~B} 2
$$

where $Y^{\prime}$ is the predicted change in circulation, $A$ is a constant, $x l$ is the regression coefficient for population change (B1) and $\times 2$ is the regression coefficient for price change (B2).

The regression technique used in this analysis was step-wise, with the computer determining first the predictor accounting for the greater variance in the criterion variable (circulation

SAll data were compiled from Editor \& Publisher International Year Book. 1970 and 1975 editions.

- Norman H. Nie et al., Stalistical Pockage for the Socual Sciences (New York: MoGraw-Hill, 1975). 
TABLE 1

Changes in Mean Circulation, Price and Population for All Daily Newspapers, 1970-75

\begin{tabular}{lrrrr}
$\quad$ Variable & \multicolumn{1}{c}{1970} & \multicolumn{1}{c}{1975} & \multicolumn{1}{c}{ Total } & Per cent \\
Circulation & $47,808.687$ & $48,718.156$ & +909.469 & 9.9 \\
Population & $134,319.750$ & $135,987.250$ & $+1,658.500$ & 6.0 \\
Price & 12.004 & 16.864 & +4.860 & 41.1
\end{tabular}

TABLE 2

Regression Coefficients in Percentage Circulation Change for Percentage Changes in Population and Price, All Newspapers

$\begin{array}{lcccc} & \text { Multiple } R & R^{2} & R^{2} \text { Change } & \begin{array}{c}\text { Regression } \\ \text { Coefficient }\end{array} \\ \text { Population } & 0.08279 & 0.00685 & 0.00685 & 0.10621 \\ \text { Price } & 0.08788 & 0.00772 & 0.00087 & -0.02718\end{array}$

change) and then the predictor variable accounting for the lesser variance. In every case, population change accounted for the greater amount of variance.

The variable entered in Step 1 was "percent change in population." Multiple $R$ was 0.08279 and $R^{2}$ (variance accounted for) was only 0.00685 . With 1 and 2192 degrees of freedom, the F-value of 15.12816 was not significant at the .05 level.

"Percent change in price" was entered in Step 2. Multiple $\mathrm{R}$ was 0.08788 with both variables entered in the equation, with an $\mathbf{R}^{2}$ of 0.00772 . Thus, "percent change in price" added only 0.00087 variance accounted for, with an F-value of $1.919(p>0.05)$.

Changes by Type of Newspaper. In terms of circulation change during the 1970 to 1975 period, Sunday newspapers had the greatest circulation gain (12.6\%) followed by morning newspapers $(+10.7 \%)$, evening newspapers $(+8.8 \%)$ and all-day newspapers $(-3.9 \%)$. Although all-day newspapers had the greatest change in price $(+52 \%)$, for the other three types of newspapers circulation change was inversely related to price change; i.e., Sunday newspapers, which had the greatest circulation growth, also had the greatest price increase $(+48 \%)$, followed by morning newspapers $(+40.8 \%)$ and evening newspapers $(+38.1 \%)$.
In the multiple regression analyses, all-day newspapers actually had a positive regression coefficient for percentage price change $(+0.12536)$, indicating that price increase clearly was not associated with circulation decrease. The other regression coefficients for price change were: morning newspapers $(-0.01976)$, evening newspapers $(-0.02823)$, Sunday newspapers $(-0.04145)$.

The final phase of the study involved comparing circulation changes of those daily newspapers which increased price from 10 to 15 cents with those which remained constant at 10 cents during the 1970-75 period.

A total of 942 newspapers increased price from 10 to 15 cents during the period. For these newspapers, the 50\% price increase was accompanied by an $8.3 \%$ circulation increase. The 536 newspapers that maintained the 10-cent price throughout the period experienced a $12.1 \%$ increase in circulation. Thus, the constant price resulted in a $3.8 \%$ greater increase in circulation.

For the combined 1,478 newspapers, mean percentage price increase was $31.87 \%$ and mean circulation increase was $9.68 \%$. The Pearsonian correlation coefficient between percentage price change and percentage circulation 
change was -0.0568 , significant at the 0.03 level. The negative correlation indicates that newspapers which increased copy price $50 \%$ did have a slightly lower percentage circulation increase, as we would expect. However, the difference of only $3.8 \%$ means that the demand curve still was highly inelastic and that the price increase would lead to substantially higher total revenue for the newspapers that increased price.

The regression equations by type of newspaper were as follows:

Morning: $\quad Y^{\prime}=0.10744+0.18788$ (per cent population change $)+(-) 0.01976$ (per cent price change)

Evening: $\quad Y^{\prime}=0.09391=0.06841 \quad$ (per cent population change) $+(-) 0.02823$ (per cent price change)

Sunday: $\mathrm{Y}^{\prime}=0.12777+0.35618$ (per cent population change) $+(-) 0.04145$ (per cent price change)

All-Day: $Y^{\prime}=0.01074+0.03963$ (per cent population change) +0.12536 (per cent price change)

Solving for a $50 \%$ price increase and holding percentage population change constant at zero, we derive the following elasticity estimates:

Morning: $0.88 \%$ circulation decrease. Evening: $1.32 \%$ circulation decrease. Sunday: $1.95 \%$ circulation decrease. AllDay: $6.29 \%$ circulation increase.

This does not suggest that raising the price on an all-day newspaper would cause a circulation increase, but it does demonstrate dramatically that the price increases during the 1970-75 period were not related to the actual circulation declines. We must search for deeper, more complex explanations of circulation changes than price and population changes, either alone or in combination.

\section{Summary and Conclusions}

Results of this study offer strong support for the hypothesis that the demand for newspaper circulation from 1970 to 1975 was highly inelastic. Although percopy prices rose $41.1 \%$ during the sixyear period, total circulation actually increased $9.9 \%$. Controlling for changes in population, the correlation between circulation and price change was slightly negative, indicating a small decrease in circulation with a much greater increase in price.

It can be concluded that at least during this time period, newspapers were grossly underpriced and newspapers lost a tremendous amount of potential revenue. Although we cannot predict with confidence that future price increases will continue to see demand remain inelastic, there is no evidence that newspapers have yet approached a point of diminishing return from price increases.

It is possible, of course, that there might be a kink in the demand curve, perhaps a psychological barrier that would result in greater elasticity beyond some point. Indeed, some newspaper managers have speculated that further price increases will lead to greater decreases in circulation.

However, another possibility needs to be explored. Perhaps we are approaching the point where price increases might be a catalyst for subscription cancellations rather than the cause. In other words, it might be an excuse to cancel a newspaper that has long since lost its relevance to some readers. If this is true, we will need to greatly expand our efforts to define the relevant role of the newspaper in our fast-changing, complex society.

As Gallup stated 15 years ago, people will continue to be receptive to price increases so long as the newspaper is worth the price to them. ${ }^{7}$

Further work is planned to attempt to more precisely determine the elasticity of demand curves for daily newspapers by including home-delivery subscription prices and measuring specific circulation responses to changes in price over time.

\section{Periodicals Publishing More About Journalism Education}

By Michael J. Bugeja

- How much is being written about journalism education these days-and by whom? The question, at first, appears

\footnotetext{
'Gallup, op. cil.
} 